\title{
Formation of visual comfort of small cities architectural environment
}

\author{
Evgeny Ponomarev ${ }^{1, *}$, Konstantin Ivshin $^{2}$, and Oksana Golubeva ${ }^{2}$ \\ ${ }^{1}$ Kazan State University of Architecture and Civil Engineering, Kazan, Russian Federation \\ ${ }^{2}$ Udmurt State University, Izhevsk, Russian Federation
}

\begin{abstract}
Statement of the problem. The aim of the study is to analyse the basic elements of creating visual comfort in the urban environment in the conditions of the renovation of the existing development of Russian small towns. Results. The main results of the research are the development of the syntactic context of architecture in urban space; the definition of the architectural language as the basis for the formation of compositional characteristics of visual comfort in urban space. Conclusions. The significance of the obtained results lies in the novelty of the approach to the mechanism of updating the architectural environment of cities based on the reform of the visual characteristics of the existing buildings; in the interpretation of architectural forms that reveal the original qualities of urban architecture. The use of the methodological basis of the mechanism of visual renewal of the architectural environment and the formation of urban space as a meaningful context that reveals individual characteristics to the viewer who is in the space of the city. At the same time, the visualfigurative context of the architectural environment of cities acquires a meaningful meaning, which allows us to comprehensively consider the process of renovation of existing buildings, including the tool for visualspatial construction of architectural solutions.
\end{abstract}

\section{Introduction}

The existing architectural and spatial organization of urban development has its own distinctive features. The main character of such spatial and compositional features forms the diversity and uniqueness of the visual image of the city [1]. At the same time, residential areas within cities differ in visual-perceived characteristics, and their visual image is not formed. Nevertheless, the visual image of the architecture of cities is necessary to create a visual comfort for the viewers who stay in them. However, in most Russian cities, the quality of the architectural environment differs as they move away from the centre in a negative way - there are no visual landmarks, dominants, and the architectural environment becomes monotonous and monotonous.

Deputy Prime Minister Marat Khusnullin proposed to spread the experience of renovation of existing areas in Moscow throughout the country. At the same time, the implementation of this task will require changes to the architectural environment, forming

\footnotetext{
* Corresponding author: 1 t_zhukova@mail.ru
} 
elements of visual comfort, thereby updating the street spaces of Grod. The comfort of the urban environment is determined not only by its functional content. The visual-perceived architectural environment also has the characteristics of visual comfort. Citizens visually read the compositional features of the three-dimensional organization of the architecture of cities. By the visible outlines of the surrounding architectural space, you can read the status and belonging of the territory to a certain area of the city. For example, the abundance of typical panel buildings indicates that this territory belongs to the peripheral zone of the city, which causes the viewer to associate with a residential area. Industrial and municipal territories of the city (with a large number of garages, warehouses, gas stations) have a peculiar architectural context, but, as a rule, such territories are located in the middle part of the city territory. The architecture of urban centres is sharply different in terms of the variety of styles, different heights of form formation, and different sizes of scale. Thus, citizens have a set of figurative stereotypes about urban areas, which confirms the thesis about architecture as a carrier of material and practical and informational and aesthetic value [2]. To give each urban area a distinctive feature, architectural originality - an urgent complex task for the development of the city, improving its image and competitiveness. It is possible to perform this task using a tool to increase the visual comfort of the existing development in the conditions of urban renovation by creating visual comfort in each residential area of the city.

\section{Materials and methods}

This study uses empirical methods of scientific research - field observation and comparative analysis. The main materials used are photo fixation of the heterogeneous urban environment (historical and modern). The theoretical method of graphic modelling is also used to determine the main results of the analysis, namely, the identification of silhouette multi-dimensional lines that determine the nature of the architectural landscape.

\subsection{The gelstatt of architectural composition}

The need to create a figurative context and use it in design practice as a meaningful identification of the features of urban space has been emphasized by many philosophers [34]. Philosophical and aesthetic thought of the beginning of the XX century began to use the term gelstatt (from the German Gestalt - "holistic image") as an interdisciplinary concept. This term was originally used in psychoanalytic as an experiment on the awareness of reality in patients [5]. In art history and architectural and artistic practice, the concept of gestate implies an assessment of the surrounding anthropogenic environment for a complete compositional system that creates a "fingerprint" of a memorable image in the viewer. According to the book "The Image of the City" by Kevin Lynch [1], there are certain visually-perceived elements of the city that can be considered as certain archetypes - paths, borders, districts, nodes, landmarks. The identified archetypes are complete and readable in the urban space modal meanings, which indicates the possibility of using them as a basis for the formation of urban space. However, spatial reconstruction of built-up areas of the city as a method of constructing architectural solutions in cities should be based primarily on the simplest compositional concepts [3], such as the silhouette, background, vertical and horizontal divisions. Modern city districts do not differ in a rich variety of architectural solutions, as a result of which, the compositional and spatial characteristics in them are poor and monotonous, which negatively affects the visual and psychological comfort of a citizen's stay in the space of the city.

In gelstatt -psychology, there are the laws of visual perception mainly for data visualization. In design and architecture, the viewer's contact with the compositional 
structure is carried out by a complex psychophysiological process [5]. Here, it is important to reflect on the visual experience as the final part of this process. The main idea of Gestalt psychology in visual perception that the image integrity is a property of the composition is perceived by the viewer, not reduced to the sum of its parts: a property of the shape, visual characteristics of the object is holistic. Such a conclusion implies a consistent set of laws of perception. Let's briefly list the main ones

1. The law of precedence or content, which implies the brevity and completeness of the meaning of the perceived composition. It is based on the fact that the human brain prefers simplicity over complexity, that is, it easily perceives and processes simple data that is more organized than complex ones.

2. The law of Continuity, states that it is a visual perception that groups compatible things, such as the juxtaposition of colour, size, shape, type, and category, which is a process of systematization.

3. The law of similarity assumes that objects with similar visual characteristics (colour, shape, size) are defined by the human brain as a group of continuity elements, and this also implies the systematization of elements.

4. The law of primary focus states that different or contrasting objects in a visual representation create a focus in perception. Such an object attracts the viewer's attention, convincing them to perceive such an object as a starting point.

5. The law of Proximity, which says that objects located next to each other are perceived by the brain as a related group that has the similarity of certain visual characteristics. At the same time, objects that are far from each other are perceived as separate, unrelated.

6. Isomorphic correspondence determines the variability of the interpretation of visible compositional features through the prism of the viewer's visual experience. Such a law can be described as the law of associations with certain emotions and actions.

7. The law of form and foundation states that objects are visually perceived by a person, either as a form or as a base, that is, the background on which other objects are placed, which determines the foreground and subsequent plans in the spatial composition.

8. The law of generality justifies the presence of a force line in the composition, which unites the movement of all the forms involved in it, that is, it creates the impression of the unity of objects connected to each other.

As a conclusion, we can conclude that gelstatt is a system of laws of visual perception, with the help of which an interactive contact of the viewer with the composition is formed. Therefore, it is necessary to use the technology of decoding the architectural composition as a control of the composite construction. In this context, we will analyse the architectural environment from the point of view of its compositional construction. Gestalt consists of the compositional parameters of architectural solutions, which are the basic basis.

Compositional foundations of architectural solutions

In the context of this article, it is proposed to consider the range of formation of architectural solutions in the spatial-planning framework by an urban resident. The variety of compositional characteristics of the architecture created today differs from the architecture of historical heritage. Modern architectural solutions have become poorer and more concise in comparison with the historical context. The era of abstraction of architectural forms and the exclusion of geometric excesses in the XX century corrected the professional three-dimensional apparatus of the architect. In parallel with the promotion of a minimalist approach to architectural shaping, a new set of tools is emerging in the architect's work. 


\section{Results}

Let's define the boundaries of the study. The architectural design actually accommodates three levels: planning and urban planning, spatial-architectural and visual-environmental (Table 1).

Table 1. Specialization of architectural design solutions.

\begin{tabular}{|c|c|c|}
\hline Architectural design & $\begin{array}{l}\text { Compositional and } \\
\text { functional parameters of } \\
\text { design solutions }\end{array}$ & $\begin{array}{l}\text { Characteristics of design } \\
\text { solutions }\end{array}$ \\
\hline \multirow[t]{3}{*}{ Urban planning } & Distance of the territory & center-periphery \\
\hline & $\begin{array}{l}\text { Composite drawing of the } \\
\text { building }\end{array}$ & $\begin{array}{l}\text { population density, number of } \\
\text { floors }\end{array}$ \\
\hline & $\begin{array}{l}\text { Modularity of residential } \\
\text { units }\end{array}$ & $\begin{array}{l}\text { block, microdistrict, residential } \\
\text { housing complex }\end{array}$ \\
\hline \multirow[t]{4}{*}{ Architectural } & Architectural styles & $\begin{array}{l}\text { quantitative enumeration of the } \\
\text { existing architectural style }\end{array}$ \\
\hline & Urban silhouette & $\begin{array}{l}\text { definition of dominants and visual } \\
\text { directions-memorable unevenness } \\
\text { of the border between the building } \\
\text { and the sky }\end{array}$ \\
\hline & Architectural landscape & $\begin{array}{l}\text { identification of different tiers by } \\
\text { the number of vertical divisions }\end{array}$ \\
\hline & Architectural expressiveness & height and multi-tiered buildings \\
\hline \multirow[t]{3}{*}{ Environmental } & Landscaping & $\begin{array}{l}\text { the presence of a barrier-free } \\
\text { environment and the priority of } \\
\text { pedestrian traffic in relation to the } \\
\text { area of well-maintained pavement } \\
\text { cars/pedestrians }\end{array}$ \\
\hline & $\begin{array}{l}\text { Traditional and cultural } \\
\text { features }\end{array}$ & $\begin{array}{l}\text { percentage heterogeneity of district } \\
\text { residents by social status, cultural } \\
\text { characteristics, and age category }\end{array}$ \\
\hline & Urban identity & $\begin{array}{l}\text { the presence of the corporate } \\
\text { identity of the urban area reflected } \\
\text { in the design of vertical surfaces } \\
\text { and color and light solutions }\end{array}$ \\
\hline
\end{tabular}

In this context, using the main architectural and compositional characteristics, we limit ourselves to the architectural level of design. Let us consider the main compositional architectural and spatial characteristics. There is an unused compositional potential of architectural solutions as a visual identifier of urban space. The artificial world of the architectural context was created by the evolution of the city for many hundreds of years, which led to the emergence of such concepts as: street, number of floors, city silhouette, architectural landscape, residential complex. The regularities of the combination of such architectural formations are involuntarily read by the viewer [2]. A meaningful interweaving of architectural characteristics creates a multi-vector urban space, forming a special and original interpretation of the spatial and environmental context of the city. Modern trends in architectural solutions allow not only to orient the viewer in the city but also to create visual and psychological comfort of staying in an urban environment. For example, the increase in the number of floors as you approach the city center is perceived by the citizen naturally; the expressiveness of the city silhouette with elements vertical dominant orients the viewer in infinity carpet buildings; multi-architectural landscape builds a hierarchy of visual senses, as you zoom in/out from the front of the building; the 
modularity of residential complexes allows kinesthetically feel the coordinate system of the city [3].

For the space of a modern city, vertical surfaces are functional information carriers. Therefore, the readability of architecture in the context of the city is closely related to the theme of facade design. For the recognition of the appearance of an urban area, first of all, three-dimensional architectural solutions for the reorganization of the building are necessary.

The main compositional characteristics of the architectural environment are the basis of architectural solutions (Table 2). From the point of view of visual-perceived characteristics, it is possible to distinguish the main ones by the example of the analysis of silhouette characteristics - dominants, tiers, gaps, unevenness. Thus, the foundations of the architectural language are symbolic signs that are read by the viewer. Architecture is a "passive value of society" [7] with educational visual properties.

Table 2. Compositional aspects of the architectural environment of cities.

\begin{tabular}{|l|l|l|}
\hline $\begin{array}{l}\text { Distance of } \\
\text { visual perception } \\
\text { of characteristics }\end{array}$ & $\begin{array}{l}\text { Characteristics of the } \\
\text { existing development }\end{array}$ & $\begin{array}{l}\text { Visually-perceived elements of } \\
\text { comfort }\end{array}$ \\
\hline $\begin{array}{l}\text { Distance more } \\
\text { than } 100 \mathrm{~m}\end{array}$ & Background Settings & Contrast \\
\cline { 3 - 3 } & & Monotony \\
\cline { 3 - 3 } $\begin{array}{l}\text { Distance less } \\
\text { than } 100 \mathrm{~m} \text { not } \\
\text { more than } 50 \mathrm{~m}\end{array}$ & $\begin{array}{l}\text { Horizontal divisions } \\
\text { (silhouette) }\end{array}$ & $\begin{array}{l}\text { Gaps in the silhouettes of urban } \\
\text { development }\end{array}$ \\
\cline { 3 - 3 } & $\begin{array}{l}\text { The presence of dominants and } \\
\text { visual directions }\end{array}$ \\
\cline { 3 - 3 } & $\begin{array}{l}\text { The density of the articulation } \\
\text { surfaces }\end{array}$ \\
\hline $\begin{array}{l}\text { Distance less } \\
\text { than } 50 \mathrm{~m}\end{array}$ & Multi-level development \\
\cline { 3 - 3 } & Number of floors \\
\cline { 3 - 3 } & $\begin{array}{l}\text { Allocation of the first floor of the } \\
\text { city }\end{array}$ \\
\hline
\end{tabular}

Architectural solutions today have a rich variety of opportunities for a comprehensive solution to the renovation of existing areas of the city. For example, changing the silhouette by the mechanism of floor-by-floor reconstruction of standard series of housing stock in residential areas; architectural solutions to eliminate empty spaces between the blind ends of buildings; the formation of architectural dominants as urban planning landmarks; the use of tiering in architectural solutions.

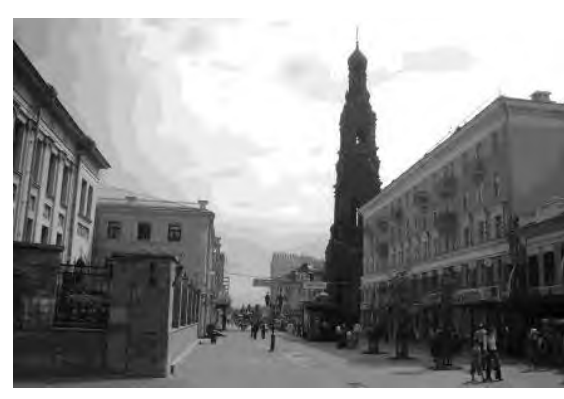

a

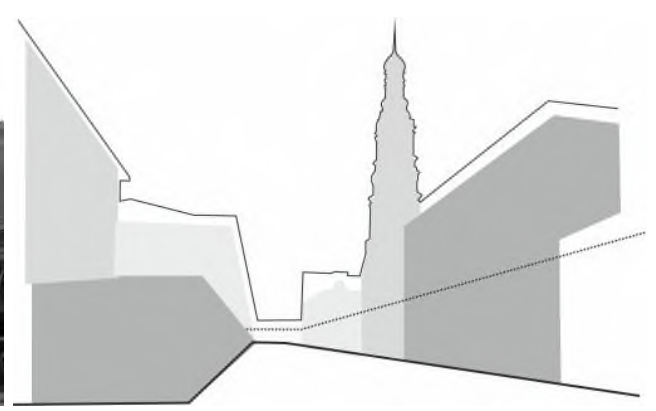

b

Fig. 1. Bauman Street in Kazan. 


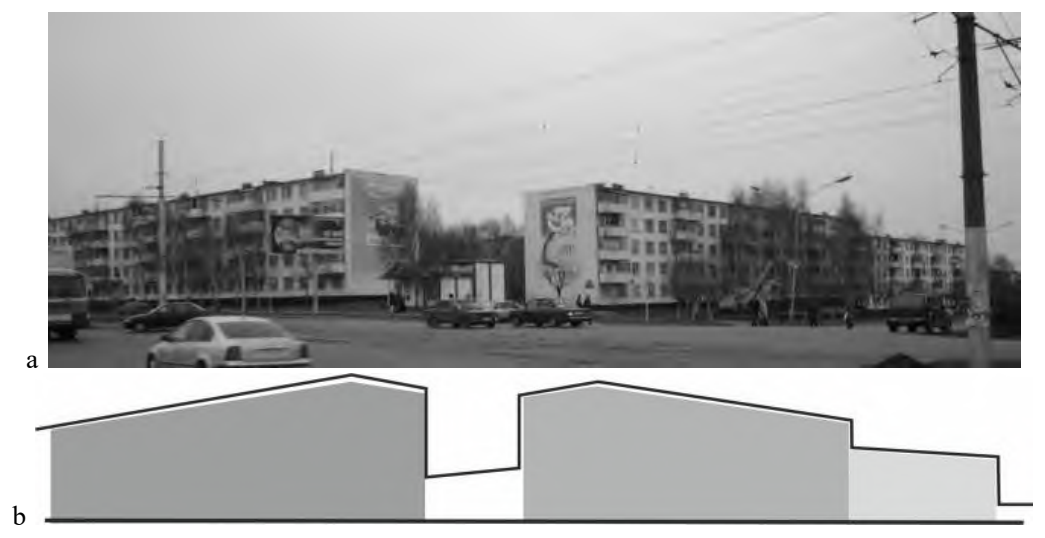

Fig. 2. Naberezhnye Chelny on the street Musa Jalil.

In the above illustrations, the main compositional characteristics indicated in Table 2 are indicated. Background characteristics are indicated by the ratio of tones, silhouette characteristics are highlighted with solid lines, and multi-story characteristics are supplemented with dotted lines. The diversity and richness of the compositional and spatial characteristics that form the syntax of the architectural language is clearly demonstrated in the historical environment (Fig. 1b) in relation to the conditional and schematic model solution of the building (Fig. 2b). Thus, we can conclude that it is necessary to use the compositional aspects of the architectural language as a spatial renovation of urban areas with existing buildings. The approach of compositional construction of the architectural environment in the context of the readable language is an updated method of urban renewal in modern cities.

For comparison, we analyzed two photos with contrasting architectural solutions Bauman Street in Kazan. The first photo (Fig. 1a) and a panoramic photo of a typical building in Naberezhnye Chelny along Musa Jalil Street (Fig. 2a), which is a typical urban landscape on the periphery of any Russian city. In the first photo (photo 1), we see a typical historical building in the central part of the city. The main compositional characteristics of architectural solutions can be identified by comparing these visual properties of architectural solutions with each other in order to express the parameters of the visual comfort of urban space.

\section{Discussion}

The architectural composition is a system of content and semantic symbols to create a visual comfort of the urban environment [6]. The existing architecture of urban areas forms visual associations. At the same time, it is necessary to take into account the different architectural occupancy of residential areas. The visual perception of each individual fragment of urban space is special and allows you to identify a specific urban area. The main part of the urban environment is depressing social areas with monotonous and dull architecture. Thus, there is an established, often negative image of the city, formed on the basis of a variety of visual characteristics of different areas. This combined image of the city has a negative connotation and requires renovation. Depressed areas of the city with negative liquidity are a common problem for all cities in Russia. Such areas, with a constant increase in social tension, are explosive in their mentality. Unreliable populations tend to exacerbate the picture by concentrating social tensions in such urban areas. The architectural environment here acts as a social constructor [7]. The architectural content of cities determines the mentality of the citizen and forms the style of urban life. "Lifestyle is 
the direct interaction of people with urban conditions, expressing what constructs the boundaries within the city, divides it and fills it with symbols and associations" [8].

The visual comfort of the viewer is more difficult to assess, but we can assume that the style of life of citizens is determined by architectural and spatial visualization [9]. The visual environment formed by architecture contributes to a meaningful choice of life in the city by the majority of the population of the countries. The free choice of the form of employment and the variety of leisure activities are the main distinctive behavioral traits inherent in citizens [10 - 12]. It is the architectural context that determines the prospects for the development of the living environment of the city's districts. The monotony and dullness of the architecture is directly correlated with the monotonous behavior of a resident of peripheral residential areas. The fragmentation of communal and industrial areas is perceived by citizens as zones for temporary residence, alienating such territories from urban life. City centers, on the contrary, allow people to diversify their leisure time. Here, different architecture changes the visual context of the city in space, which relaxes the viewer, creating positive emotions of psychosocial perception. Stylistic heterogeneity and the layering of cultural layers of different time periods positively affects the human psyche and attracts citizens, arousing their interest [13-14] and forms the identification semantics of the place.

The city is geographically segregated as a socio-cultural entity. In most cities, there is a cross-section of territories of different social statuses. Over time, a certain visual and psychological attitude of residents to a certain territory is formed, including on the basis of compositional elements of the architectural environment characteristic of a particular urban area. Citizens visually distinguish the difference between the architecture of different urban areas by their visual characteristics. Thus, the architectural environment acts as a constructor of the social identifier of the urban area. The city is the repository of all the achievements of civilization. The architecture of the city as the main framework of the living space of cities accumulates the results of civilization and is a developing and educational environment. Thus, it is architecture as the main visual background that reveals the positive potential of human achievements. The fragmentation of the urban area by social status is directly correlated with the architectural parameters of the given city territory. Urban areas built up with "social housing" have very specific architectural characteristics. Namely, standard housing, low-cost landscaping, minimal environmental design. Central, elite urban areas have sharply different architectural and environmental characteristics - expressive architecture, comfortable, well-maintained environment with abundant infrastructure. This urban area is filled with a high social potential of the living space.

\section{Conclusion}

The combination of the use of compositional features of architectural solutions will make it possible to form a full-fledged compositionally built architectural space of the city in a single residential area in the conditions of the renovation of the existing development. The quality of architectural solutions of spatial reorganization conceptually determines the characteristic parameters of visual and psychological comfort by functional and quantitative indicators, such as background, silhouette, and different stories.

The interrelation of the elements of the system of the spatial organization of the composite elements of the architecture of the city is, first of all, the main task of the renovation of the existing buildings, including a revision of design solutions for the selected residential area of the city. To create visual comfort, it is necessary to create a holistic architectural image-gelstatt, thereby improving the quality of visual and psychological comfort of citizens. Thus, the renovation of residential areas with existing buildings in 
cities will create conditions for psychological and physiological unloading of the viewer and determine the necessary set of architectural and design solutions.

\section{Reference}

1. K. Lynch, The image of the city (Moscow, Stroyzdat, 1982)

2. T. V. Chaplya, JII 3, 2 (2016)

3. P. N. Luning, The language of architecture. Essays on Architectural theory (Moskov, Delo, 2018)

4. A.V. Ikonnikov, Artistic language of architecture (Moscow, Iskusstvo, 1985)

5. D. Y. Porozova, USPU 3 (2012)

6. V. V. Ivanova, M. A. Zykova, Whether 17, 2 (2017)

7. I.G. Paliy, ISPH 10 (2005)

8. V. N. Burtonova, JP 25, 12 (2017)

9. S. M. Mikhailov, A. S. Mikhailova, A\&CofR,1, (2018)

10. E. Manzini, Design, when everyone is designing (Cambridge, MIT Press, 2015)

11. L. Wirth, AjofS 44 (1938)

12. G. Nelson, Problems of design. (New York, Whiney Library of Design, Division, 1957)

13. L. Kiroff, Visual language in architectural design Auckland (New Zealand Institute of technology, 2002)

14. T. Schielke, The Language of Lighting: Applying Semiotics in the Evaluation of Lighting Design, LEUKOS 15, 2-3, 227-248 (2019) 